\title{
A proposal of a service learning project, using Linear Models, Global analysis, and Optimization
}

\author{
Maifer R. Demirbec, PH.D. \\ Math Department, La Guardia Community College, New York City
}

\section{Introduction}

I propose as a research service learning project "A model of Implementation the Agro-tourism in Romanian Sea-side Area (Dobrodgea) on the basis of USA Experience", that I view as a part of teaching about globalization, and involving of mathematics in direct service to the community, which includes also the indirect service, that are preparation and reflection about the service experience.I choose that application for the following reasons:-at present, the tourism in Dobrodgea zone ensures $45 \%$ of the Romanian tourism, including almost all kinds of tourism developed in Romania, inclusively the agro-tourism (I mean the rural one) of relatively incipient forms;

the touristic vacation at the Romanian sea-side of Black Sea is one of the most important wealth of Romania, which, in spite of so many unfavorable conditions and evolutions, motivates the holiday tourism, therapeutics, balneary, cultural, rural, business tourism, etc the tourism in the area represents a future development and potentialities due to the geographical position of connecting Romania to Middle East and Europe through the Danube-Black Sea channel; the tourism industry is influenced, to a great extent, by the development of agro alimentary production, because the flows tourists mean, sometimes, millions of people which must be nourished, for a determined period of time or even continuously, besides the local population. The agro tourism represents a main direction of Romanian tourism development; the rural tourism is a real important field, and could become in the future a source of additional incomes of the disadvantaged population, from the view point of isolation from the urban centers;from the point of view of ecological criteria, the research emphasize that Romania presents some ecological advantages; the tourists can find here natural food, but from different reasons, does not preserve unchanged.

By outlining all these arguments, I have motivated the importance of the study, both for Romania and for the agro tourism field, generally with connections between the classroom theory and the service learning activity, which general education principlesthat will be addressed by the Service Learning Objectives referring to: Academic Literacy, Communication, Civic Engagement, and Globalization.My contribution to this program will consists also in the fact that I shall have the opportunity to work with students trained in this field, and to be in touch with the decision making factors, by adding mark of knowledge and upgrading to all those which are interested in knowing and turning to account the natural and human potential, namely, the future experts and investors.

I shall make the following suggestions in the study:

to diagnose the rural compared tourism of partners, according to the analysis of their offers;

to enumerate similitudes and contrasts, with the aid of certain indicators calculated by mathematical methods, using the coefficient of similarity of "B Roy" and that of similitude of M Stoica. ${ }^{1}$

to adjust the moderate development scenario used in my doctor's degree thesis to the condition in California and Romania, by pointing out the unbalances among the tourism requirements, of experienced countries in the field of rural tourism and the current conditions in Dobrodgea rural tourism.

According to my results, I intend to propose a trans-national strategy, because it includes the following advantages as against the other forms of strategies:

a) I use the effects of learning curve;

b) I use the placement savings;

c) I adjust the merchandise supply and marketing proceedings to the local environment conditions;

d) I make profits from the experiences gained at a global level.

I shall work out the conclusions and proposals of the project, by taking into account the disadvantages which the trans-national strategy involves, due to the problems of organizational nature. I notice that this study will imply knowledge of applied mathematics, economy of tourism, management, marketing, use of computer applications programs, international strategies of firms, of practicing in the field of tourism. I have gained the

\footnotetext{
${ }^{1}$ Quantitative Methods in Management, By Marin Andrei, Marcel Stoica, Florica Luban, Ed. Economica,1998, Bucuresti, pag.10919
} 
practical experience in production and during the practicing month with students, when I have been their adviser in different branches of marketing and management.

Further on, I want to briefly point out some of the implications related to this study, because it can be analyzed also from the view point of an important future investment project:

- By carefully observing the ecological criteria, in order to evaluate and to warn the ecological risks derived from such a savage exploitation of zone natural potential, Romania requires a technical assistance in this field, with equipment; they could be supplied from a partnership relation with American state;

- The multilateral implication, both in Dobrodgea and in California, have influenced and still to the future travel motivation. As regards this aspect, there is important to study the cultural traditions (ethnography, folklore, art cuisine, and art craft) which in Dobrodgea are put into practice by summer festivities. I have to study all these aspects concerning the Californian tourism, to what extend they are rendered profitable by the Californian tourism;

- I have started from the premises that taking as standard of exigency the American Tourists, I can assure you that the standards offered by the Dobrodgea agro tourism will meet the exigencies of tourists all over the developed countries.

Under the conditions of the moderate development scenario, I take into consideration the agricultural soils of viable farms (about 50-200), by using the experience of the countries whose agriculture is structured in large farms. The scenario considers the appearance of smalls and medium enterprises of processing the agricultural product, as well as the trans-national farms in the field. This fact will increase the population incomes and will substantially change the food consumption that will be considerably increased. Consequently, a series of structural changes of the consumption model will take place, at least within the medium and over medium incomes of population. The benefic aspects of this scenario will be gradually noticed in the home market, by substantially satisfying the demand of autochthonous products and by gradually revitalizing of the agro alimentary products export, where Romania has already got a competitive advantage.

All of this professional arguments encourage me to be confident in my potential to support that present research study, as a grand purpose. At the same time, I think that Romania, as a country, and the Romanian people deserve a developed tourism. In case, I will finalize, the experience gained from it, will certify that the universities centers with apparently different cultures, have same criteria of values, namely, "the work".

In other words, the quality of an activity field is firstly given by the factor of human resources, namely, by specialists and their results; "it is the man who gives value to the place".

Consequently, the quality of my experience gained abroad will be reflected in the quality of the generations of specialists, graduates of the university where I teach.

\section{References}

[1]. Stoica, Marcel and MaiferDemirbec. Case and practical applications concerning the economic forecast. , Ed. Matrix Rom, Bucharest, 2002, ISBN 973-685-418-3

[2]. Demirbec, Maifer. Prospects of developing in Dobrogean tourism. , Ed. Matrix Rom, Bucharest, 2003, ISBN 973-685-602-X

[3]. BMCC Service Learning Faculty Development, 24 February 2017, WORKSHOP 